\title{
Study of Dislocations Generated by Thermal Cycling in Ni-Ti-Co Shape Memory Alloys
}

\author{
J. Pons*,**(1) L. Jordan*,***, J.P. Morniroli**** and R. Portier*,** \\ * Lab. Métallurgie Structurale, ENSCP, 11 rue Pierre et Marie Curie, 75231 Paris cedex 05, France \\ ** Centre d'Etudes de Chimie Métallurgique, CNRS, 15 rue G. Urbain, 94407 Vitry-sur-Seine, France \\ *** Faculté de Chirurgie Dentaire, 5 rue Garancière, 75006 Paris cedex 06, France \\ **** Lab. de Métallurgie Physique, Université de Lille I, Bât. C6, 59655 Villeneuve d'Ascq cedex, France
}

\begin{abstract}
In the present work we report some results concerning the evolutions of transformation temperatures and microstructure during thermal cycling in Ti- $47 \% \mathrm{Ni}-3 \% \mathrm{Co}$ (atomic percent). In the case of hulk material (obtained by a conventional solidification method) high amounts of dislocations form during cycling, which produce a considerable evolution of the transformation temperatures (up $10 \sim 40 \mathrm{~K}$ ), while in meltspun material containing a dispersion of fine precipitates, the formation of dislocations during thermal cycling is highly reduced, giving rise to stable transformation temperatures. The dislocation characteristics have been analysed by means of two-beam condition observations as well as the Large Angle Convergent Beam Electron Diffraction technique. Some energetical considerations concerning the dislocations are pointed out to interpret the evolution of transformation temperatures.
\end{abstract}

\section{INTRODUCTION}

The evolution of the martensitic transformation during thermal cycling (repetition of the temperature induced transformation) in NiTi alloys has been studied in several works [1,2]. A decrease of transformation temperatures of about $30-40 \mathrm{~K}$ has been observed after the first $10-20$ cycles in annealed specimens, whereas in the case of $\mathrm{Ni}$-rich aged specimens, containing dispersions of fine precipitates inside the B2 matrix, the effect of thermal cycling is much less pronounced [1]. The formation of dislocations during the martensitic transformation cycling has been pointed out [1-5], and the effects of cycling have been attributed to these dislocations, although a detailed study of them has not been reported.

In the present work we shall report some results concerning the reproducibility of the transformation (thermal cycling up to $\sim 20$ cycles) in a NiTiCo alloy with different initial microstructures (rolled bulk alloy, annealed bulk alloy and meltspun alloy). The dislocations present in the different cases have been analysed.

\section{EXPERIMENTAL}

The $\mathrm{Ti}-47 \%$ at $\mathrm{Ni}$ - 3\%at Co alloy was prepared from $99.99 \% \mathrm{Ti}, 99.99 \% \mathrm{Ni}, 99.99 \% \mathrm{Co}$, by melting in a high frequency induction furnace under an argon atmosphere. The ingots were hot rolled to cylindrical rods of $5 \mathrm{~mm}$ diameter. A portion of alloy was meltspun under an helium atmosphere by injection of the melt at $1660 \mathrm{~K}$ on a steel wheel rotating at $19 \mathrm{~m} / \mathrm{s}$. Ribbons of $8 \mathrm{~mm}$ widthness and $0.05 \mathrm{~mm}$ thickness were obtained. Some bulk and meltspun samples were annealed at different temperatures in a vacuum $\left(10^{-5}\right.$ $\mathrm{Pa}$ ) furnace and slowly cooled to room temperature.

DSC experiments (Mettler 30 system TA4000) were carried out to measure the evolution of transformation temperatures during the first 10-20 cycles. The TEM observations were performed on a Jeol 2000 FX microscope operating at $200 \mathrm{kV}$. The analysis of dislocations was carried out by the conventional method (looking for the extinction of contrast in two-beam condition) as well as by Large Angle Convergent Beam Electron Diffraction (LACBED). The LACBED experiments were performed in a Philips CM30 microscope.

(1) Present address: Dept. de Física, Universitat de les Illes Balears, ctra. de Valldemossa km 7,5, 07071 Palma de Mallorca, Spain 


\section{RESULTS}

\subsection{Calorimetric results}

In the case of bulk material, the thermograms have a typical form as shown in figure $1 \mathrm{a}$. Two exothermic peaks appear on cooling (B2 $\rightarrow R$ and $R \rightarrow$ Martensite (B19) transformations) and only one endothermic peak $(\mathrm{M} \rightarrow \mathrm{B} 2)$ on heating. We will consider as characteristic transformation temperatures those corresponding to the maxima of the peaks, which will be denoted as $R, M$ and $A$ for the $B 2 \rightarrow R, R \rightarrow M$ and $M \rightarrow B 2$ transformations, respectively. The evolution of these temperatures for samples annealed at different temperatures is plotted in figure $1 \mathrm{~b}$. The $\mathrm{R}$ temperature is constant during cycling, while a decrease of martensitic transformation temperatures is clearly observable during the first transformation cycles, specially in the specimens annealed at higher temperatures. The evolution is progressively reduced until the 20th cycle, from where a stable transformation is obtained [6]. It is interesting to note that the differently thermally treated samples reach the same "final state", with the same transformation temperatures and hysteresis.

The meltspun material shows lower transformation temperatures and broadened transformation peaks [7]. In what concerns to the reproductibility of transformation, the behaviour is also very different in relation to the bulk samples. In this case, practically no evolution of the transformations (either, $\mathrm{R}$ and martensitic transformations) has been observed, at least during the first 5 cycles.
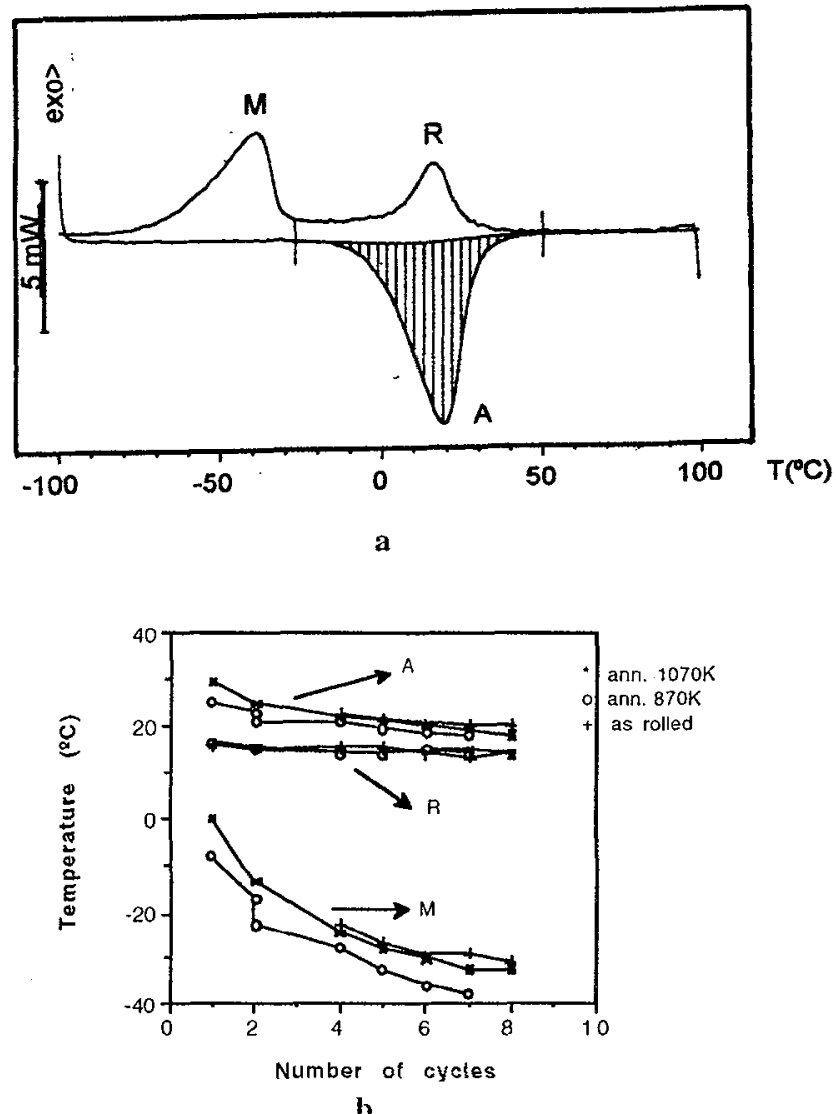

Figure 1. a) Characteristic thermogram of a bulk specimen showing the peaks observed on cooling and heating. b) Evolution of transformation temperatures with the number of cycles for the as rolled and annealed bulk material. 


\subsection{Initial microstructures}

The TEM observations show that the as-rolled bulk material contains a considerable amount of dislocations, due to the plastic deformation produced during rolling (figure 2). After annealing at increasing temperatures, the amount of dislocations is progressively reduced. The annealing treatment at $1120 \mathrm{~K}$ eliminates almost completely all the dislocations produced by rolling. In all bulk alloys, some $\mathrm{Ti}_{2} \mathrm{Ni}$ particles have been observed at the grain boundaries.

In the case of meltspun material, a dispersion of very fine precipitates $(\sim 20 \mathrm{~nm})$ inside the grains together with some dislocations were observed. During ageing at $1120 \mathrm{~K}$ the microstructure changes. After 2 hours at $1120 \mathrm{~K}$, the precipitates grow up to a size of about $100 \mathrm{~nm}$ (figure 3 ). The electron diffraction patterns of these precipitates correspond to the $\mathrm{Ti}_{2} \mathrm{Ni}$ phase. After 4 hours, the precipitate size is about $150 \mathrm{~nm}$. After $10 \mathrm{~h}$ another kind of precipitates is also ohserved. They have a lenticular shape and the SADP correspond to the $\mathrm{Ti}_{3} \mathrm{Ni}_{4}$ phase.

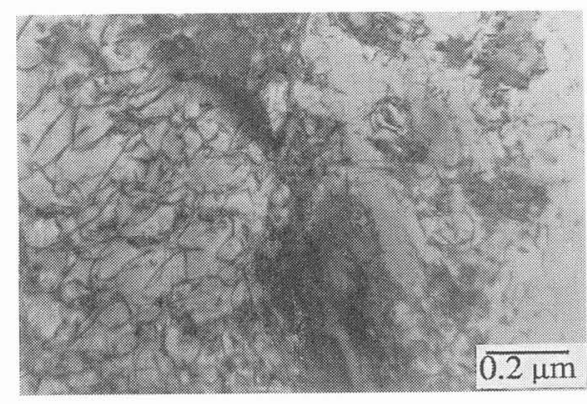

Figure 2. Image of dislocations present in an asrolled bulk specimen.

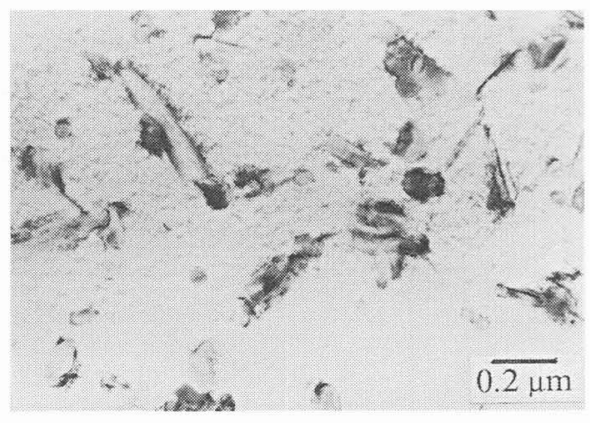

Figure 3. TEM image of precipitates and dislocations present after 2 hour annealing at $1070 \mathrm{~K}$, in the meltspun alloy.

\subsection{Microstructures after thermal cycling}

The figure 4 corresponds to the bulk matciial annealed at $1120 \mathrm{~K}$ after one transformation cycle. It has to be remembered that the so treated material docs not contain dislocations prior to the martensitic transformation cycling. So, it is evident that there is a formation of a high amount of dislocations during the transformation-backtransformation process. The density of dislocations increases with the number of cycles, reaching a final state (after $10-20$ cycles) containing a very high density (figure 5 ).

Conversely, in the meltspun material the formation of dislocations by thermal cycling is much more reduced. As an example, we can compare the figure 3 (without transformation cycles) with figure 6 (sample with 10 thermal cycles).

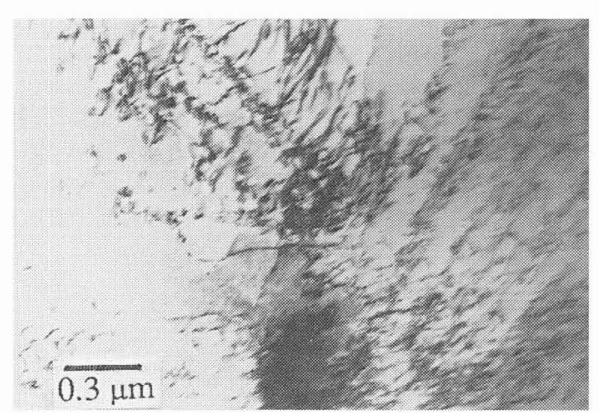

Figure 4. Image of distocations formed alter 1 thermal cycle in a sample of the bulk alloy annealed at $1070 \mathrm{~K}$.

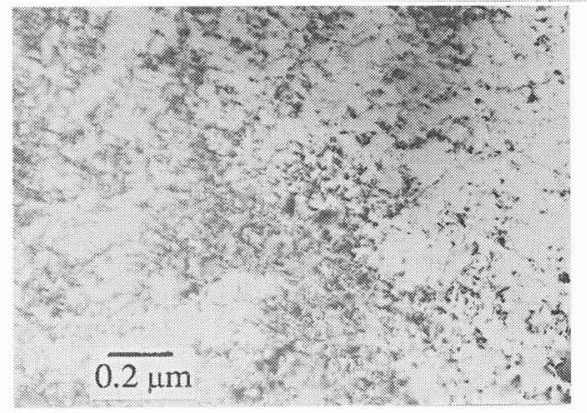

Figure 5. Dislocations tangles formed after 20 thermal cycles in a bulk alloy specimen annealed at $870 \mathrm{~K}$. 


\subsection{Analysis of dislocations}

The dislocations formed by thermal cycling have been analysed in a specimen annealed at $800^{\circ} \mathrm{C}$ with 1 thermal cycle, considering only the isolated dislocations (in the dense dislocation tangles it is impossible to perform such study). The majority of dislocations have line direction $\mathbf{u}=<111\rangle$, although some segments lie on other directions ( $<100\rangle$ among them). The Burgers vector, obtained with the $\mathbf{g} \cdot \mathbf{b}=0$ criterion for the extinction of the contrast, has been found to $b e=<=100>$ (the figure 7 shows the extinction of the contrast for the $\mathrm{g}=200$ ). The dislocations are often arranged in bands along different orientations.

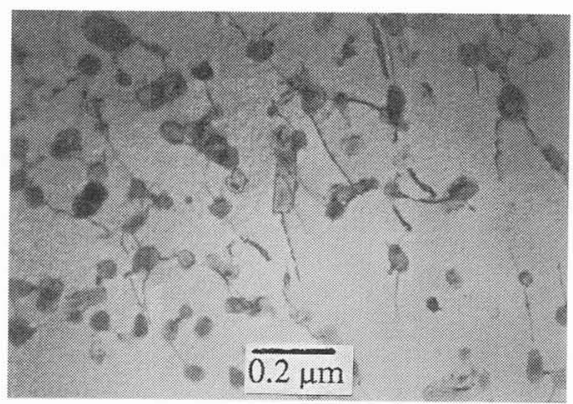

I'igure 0. Precipilates and disiocations in a meltspun sample annealed at $1070 \mathrm{~K}$ and 10 thermal cycles.

The majority of dislocations present in the rolled material (without any transformation cycle) fit with a Burgers vector $\mathbf{b}=\langle 111\rangle$. This is, in fact, the most usual kind of dislocations for the plastic deformation of bec alloys. In the cycled meltspun alloys we found both kinds of dislocations, i.e. $\langle 100\rangle$ and $\langle 111\rangle$ type.

The determination of Burgers vector has also been performed by LACBED. The Large Angle Convergent Beam Electron Diffraction method certainely is one of the most optimised technique in electron microscopy because a single micrograph provides informations both in Fourier and direct spaces. An incident electron beam with large convergence semi-angle (about $3^{\circ}$ ) is focussed on the object plane, but the specimen is slightly raised from this position. As a consequence, the diffiacted and the transmitted beams coming from the same point of the exit face of the specimen are separated in the image plane, where a small aperture selects the transmitted beams for the formation of a bright field LACBED which is observed at the level of the objective back focal plane (diffraction plane). On the micrograph, we observe a set of dark lines (Bragg lines) which represent the loci on the specimen of the exact Bragg positions superimposed to a shadow image of the specimen which is not exactly located on the object plane. The identification of the lines are obtained by the comparison of the experimental LACBED pattern with a theoretical one. When a Bragg line crosses a oriented dislocation line, the strain field of the dislocation produces typical fringes at the intersection. With $\mathbf{n}$ the number of interfringes, $\mathbf{g}$ the Bragg line indices and $\mathbf{b}$ the Burgers vector of the dislocation, we have $\mathbf{n}=\mathbf{g} \cdot \mathbf{b}$ (Cherns and Preston rules) [8-10]. This method is very efficient because the two-beam condition is easily fulfilled and with at least two independent Bragg lines, the Burgers vector of a dislocation is obtained. We used this method in our study, confirming the results obtained by the conventional procedure, i.e. dislocations formed by thermal cycling being of $<100>$-type (figure 8 ). In the as rolled and meltspun specimens, besides the $<111>$ dislocations, in some cases the LACBED patterns fit with $<110>$ and $<222>$-type Burgers vectors as well.

\section{DISCUSSION}

The comparison of all the experimental results makes evident that the evolution of the martensitic transformation temperatures observed in the bulk material is due to the high amounts of dislocations formed during thermal cycling. The R transformation is, nevertheless, not affected by the dislocations. In the case of meltspun alloys containing fine dispersions of precipitates, the formation of dislocations is much more reduced, giving rise to a more reproducible transformation. Similar conclusions were obtained 
by Miyazaki et al in NiTi [1]. These authors studied, among others, aged Ni-rich NiTi bulk alloys containing fine dispersions of precipitates. In that case they also obtained an absence of evolution of transformation temperatures during cycling, connected with a very reduced formation of dislocations. So, the behaviour obtained in our meltspun NiTiCo ribbons has to be attributed to the presence of the precipitate dispersions, which, in turn, are formed as a consequence of the rapid solidification procedure.
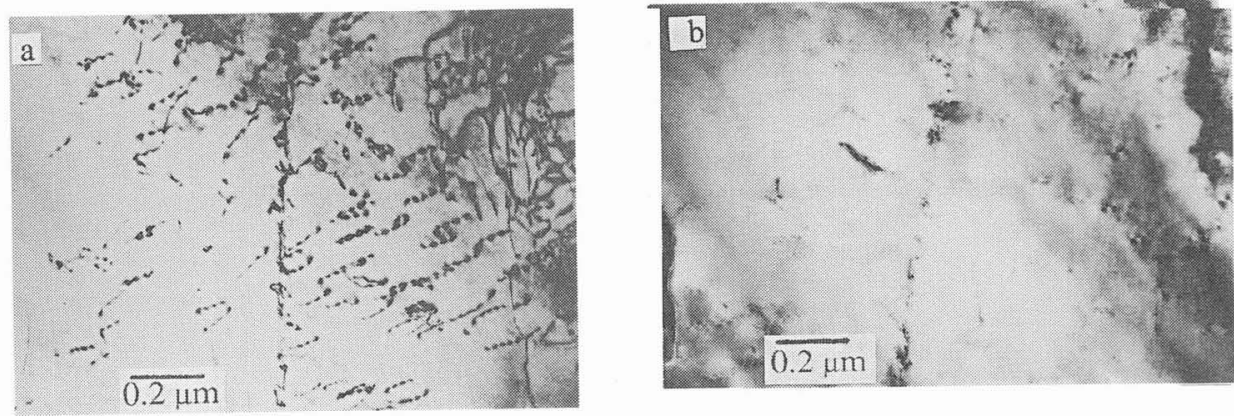

Figure 7. Extinction of the dislocalions under two-beam condition. a) image taken with $g=\overline{1} 11 \quad$ b) image (aken with $g=200$

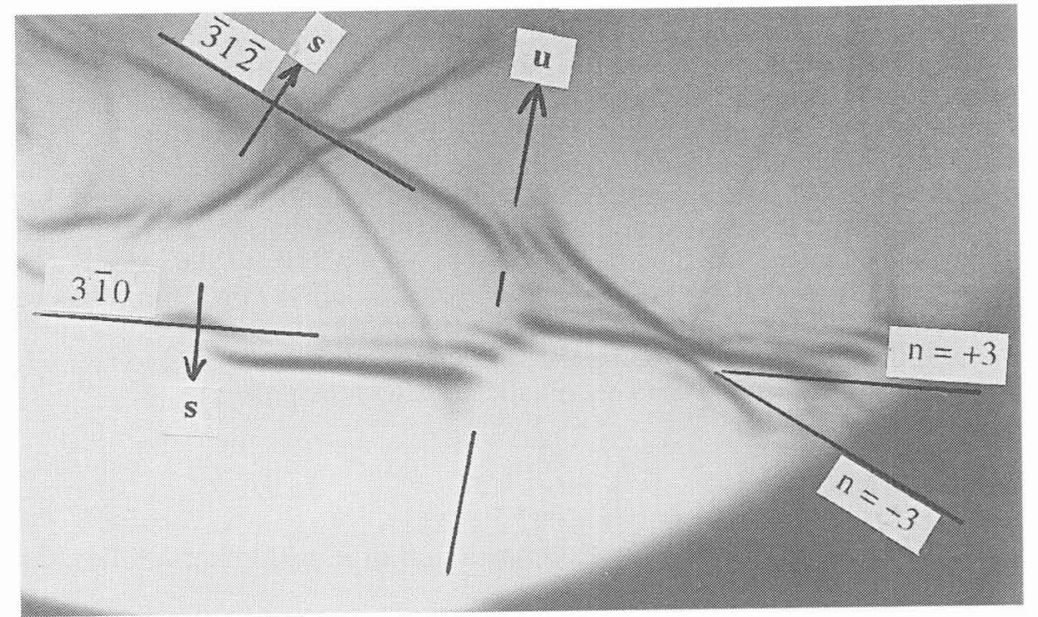

Figure 8. Burgers vector determination by LACBED. u-vector is the direction of the dislocation line, $s$-vector indicates the sign of the excitation error outside of the Bragg line and $n$ is the number of interfringes (the sign is given by the Cherns and Preston rules). With $\mathbf{b}=100$ (confirmed with other Bragg lines), we have $(100)(3 \overline{\mathrm{T}} 0)=3$

It is worth to note the similarities with $\mathrm{Cu}-\mathrm{Zn}-\mathrm{Al}$ alloys. In this system, $<100>$-type dislocations, mainly with $\mathbf{u}=<111>$ line directions, are also formed by thermal cycling, although in quite smaller amounts [1113]. When a dispersion of fine $\gamma$-phase precipitates is present, the formation of dislocations is also reduced in relation to the precipitate-free material [14]. Nevertheless, in NiTiCo, the reduction in the formation of dislocations by thermal cycling when a dispersion of precipitates exists (meltspun material) is much more pronounced.

In ref [13], devoted to $\mathrm{CuZnAl}$, some energetical considerations were taken into account in order to interpret the shift of transformation temperatures to lower values when dislocations are present in the material. A similar study is now being performed in the case of NiTi-type alloys. In this sense we can make the following preliminar consideration: being the martensitic transformation a diffusionless process, the defects (in our case, dislocations) present in austenite are inherited by the martensite. Due to the shape 
change coming with the transformation, the length of the Burgers vector of the dislocation changes when passing from austenite to martensite. The relative Burgers vector length change has been calculated using the transformation matrix obtained by Matsumoto et al [15] with the phenomenological theory of martensitic transformations. The results are shown in table 1:

Table 1. Change of $\langle 100\rangle$ and $\langle 111\rangle$ vectors created by the martensitic transformation (calculated with the transformation matrix obtained by Matsumoto $e t$ al $[15])$, and relative length change: $\Delta \mathrm{l}=100\left(\mathrm{l}_{\mathrm{mart}^{-1}} \mathrm{l}_{\text {aust }}\right) / \mathrm{l}_{\text {aust }}$

\begin{tabular}{lrrrr} 
Austenite & \multicolumn{3}{c}{ Martensite } & $\Delta \mathrm{l}(\%)$ \\
\hline \hline 001 & 0,0117 & $-0,7199$ & $-0,6925$ & $-0,09$ \\
010 & 0,0221 & 0,6940 & 0,7169 & $-0,19$ \\
100 & $-1,0067$ & 0,0068 & $-0,1431$ & $+1,65$ \\
111 & $-0,9729$ & $-0,0190$ & $-1,5526$ & $+5,79$ \\
$\overline{1} \overline{1} 1$ & $-1,0171$ & $-1,4071$ & $-0,8187$ & $+0,47$ \\
$\overline{1} 11$ & 1,0406 & $-0,0327$ & $-1,2664$ & $-5,34$ \\
$11 \overline{1}$ & $-0,9964$ & 1,4208 & $-0,1675$ & $+0,65$ \\
\hline \hline
\end{tabular}

For $<100>-$ type dislocations, the most significant length changes are positive, i.e. the length of the vector is higher in martensite. For the <111>-type dislocations, it is also positive in the majority of cases. The energy of a dislocation is proportional to the square of its Burgers vector length, then, the energy of many dislocations should be higher in martensite (for an exact calculation, it is necessary to consider also the elastic constants of both phases). Then, the presence of dislocations brings about a relative increase of the free energy of martensite in relation to the austenite (the free energies of both phases are increased by the presence of dislocations, but the increment is higher in martensite, due to the higher energy of the dislocations in this phase). As a consequence, the transformation temperature is lowered, as indeed observed. In the same sense, it is worth noting that both, the dislocations formed by the transformation $(b=<100>)$ and the dislocations formed by rolling $(b=<111>)$ would have the same qualitative effect. This fact is also experimentally observed: in bulk material, the samples containing dislocations formed by rolling have lower transformation temperatures (for the first cycle) than the samples annealed at $1120 \mathrm{~K}$. In what concerns to the $\mathrm{R}$ transformation, being the lattice distortion associated to this transformation very small, the presence of the dislocations does not practically affect the process.

\section{ACKNOWLEDGEMENTS}

JP. acknowledges the DGICyT (Spain) for the concession of a postdoctoral fellowship of MEC-MRT program.

\section{REFERENCES}

1. Miyazaki S., Igo Y., Otsuka K.; Acta Metall. 34 (1986) 2045

2. Tadaki T., Nakata Y., Shimizu K.; Trans. of the Japan Inst. of Met. 28 (1987) 883

3. Sandrock G.D., Perkins A.J., Hehemann R.F.; Metall. Trans. 2 (1971) 2769

4. Wayman C.M., Cornelis I., Shimizu K.; Scripta Metall. 6 (1972) 115

5. Perkins J.; Metall. Trans. 4 (1973) 2709

6. Jordan L.; Ph D Thesis, Ecole Nationale Supérieure de Chimie de Paris, 1993

7. Rimaux C.; DEA Thesis, Ecole Nationale Supérieure de Chimie de Paris, 1993

8. Cherns D., Preston A.R.; Proc. XIth Int. Congr. on Electron Microscopy, Kyoto,Japan, 1986 p. 721

9. Tanaka M., Terauchi M., Kaneyama T.; CBED II, Jeol Ltd., 1988

10. Cherns D., Preston A.R.; J. Electr. Microsc. Technique 13 (1989) 111

11. Kajiwara S., Kikuchi T.; Acta Metall. 30 (1982) 589

12. Ríos-Jara D., Guénin G.; Acta Metall. 35 (1987) 109

13. Pons J., Lovey F.C., Cesari E.; Acta Metall. Mater. 38 (1990) 2733

14. Pons J., Cesari E.; Acta Metall. Mater. 41 (1993) 2547

15. Matsumoto O., Miyazaki S., Otsuka K., Tamura H.; Acta Metall. 35 (1987) 2137 